\title{
Symptomatic polyneuropathy in human immunodeficiency virus antibody seropositive men with and without immune deficiency: a comparative electrophysiological study
}

\author{
Torben Smith, Johannes Jakobsen, Johannes Gaub, Werner Trojaborg
}

\begin{abstract}
Symptomatic polyneuropathy in human immunodeficiency virus (HIV) infection was studied in ten men with acquired immunodeficiency syndrome (AIDS) and in ten men without the immune deficiency. In both groups of patients electrophysiological signs of polyneuropathy of the axonal type were present in the sural, median and peroneal nerves. The AIDS patients had a greater reduction of the mean (SD) sural nerve action potential, $3 \cdot 1(2 \cdot 7) \mu \mathrm{V}$, than in patients without AIDS, $10 \cdot 2(6 \cdot 1) \mu V$ (p $<0.01$ ) and greater slowing of peroneal nerve conduction velocity, $42 \cdot 6$ $(1.4) \mathrm{m} / \mathrm{s}$ in AIDS patients versus 52.6 $(3 \cdot 3) \mathrm{m} / \mathrm{s}$ in patients without AIDS (p $<0.0001)$. These findings indicate that in most HIV infected patients the severity but not the type of neuropathy depends on whether an immune deficient state has developed. Seven patients with symptomatic polyneuropathy were treated with azidothymidine (AZT) for an average of 10 months and compared with a group of five untreated patients with similar symptoms. No effect of AZT treatment on sural or median nerve amplitude or conduction velocity or on the vibratory or temperature thresholds was observed.
\end{abstract}

Human immunodeficiency virus (HIV) infection is associated with several forms of peripheral neuropathy including distal symmetrical polyneuropathy, inflammatory demyelinating polyneuropathy and mononeuropathies. ${ }^{1-10}$ The distal symmetrical polyneuropathy occurs in a large proportion of acquired immunodeficiency syndrome (AIDS) patients and is characterised by mild slowing of conduction velocity, amplitude reduction of the action potential and fibre loss. In contrast, chronic or acute inflammatory demyelinating polyneuropathy can be the presenting symptom of HIV infection and are held to be the predominant form of symptomatic polyneuropathy in HIV infected subjects without AIDS. This condition is characterised by considerable slowing of the conduction velocity, conduction block and pathologically by inflammatory infiltrates and demyelination.

To examine whether the predominant forms of symptomatic polyneuropathy in HIV seropositive patients with and without AIDS are different a clinical and electrophysiological study was carried out on two groups of ten patients each. In addition, we report the results of a small and prospective study on the effect of azidothymidine (AZT) treatment in seven of the twenty patients studied.

\section{Patients and methods}

Patients

Ten homosexual men with AIDS and ten HIV seropositive homosexual immune competent men, who were referred to the department of clinical neurophysiology for diagnosis of symptoms compatible with polyneuropathy were included in the study. Informed consent was obtained from the two groups. The presence of HIV antibody was confirmed by Western Blot analysis. The time of seroconversion was unknown. In seven of these patients (two had AIDS, five were HIVseropositive without AIDS) treatment with AZT (1000-1200 mg each day) was started and a follow up study was carried out after a treatment period of 10 (3) months. Five of the untreated patients were used as controls. No toxic or metabolic causes of the neuropathy were found and there was no family history of neuromuscular disorders. At the clinical examination special attention was paid to symptoms commonly associated with peripheral neuropathy.

The vibratory perception threshold was determined on the pulp of the thumb and on the pulp of the big toe. The vibratory stimulus was harmonic mechanical oscillations of $100 \mathrm{~Hz}$, delivered by an electromagnetically driven vibrator (Biothesiometer, Biomedical Instruments, Newbury, Ohio). The values were compared with normal subjects matched for age and sex. ${ }^{11}$

Cutaneous thermal thresholds of the foot were tested using a portable computer system. $^{12}$ A sequence of dynamic thermal test stimuli (cold or warm) of varying intensities was applied to the patient's skin (sole of the foot) using a thermoelectric module which effected a temperature change according to the Peltier principle. The polarity of the current could be set so that the device either heated or cooled the skin, and thresholds for each were measured separately and compared with values from normal subjects matched for age. 
Table 1 Clinical and electrophysiological features of $10 \mathrm{HIV}$-seropositive patients without AIDS and 10 patients with AIDS

\begin{tabular}{|c|c|c|c|}
\hline & $\begin{array}{l}\text { HIV-serpositive patients } \\
\text { without AIDS }\end{array}$ & AIDS patients & Normal controls \\
\hline & \multicolumn{2}{|c|}{ Mean (SD) } & \\
\hline $\begin{array}{l}\text { Age (years) } \\
\text { Recognised duration of HIV/AIDS (months) } \\
\text { Duration of symptoms (months) }\end{array}$ & $\begin{array}{l}40(7 \cdot 7) \\
20(10 \cdot 9) \\
12(12 \cdot 7)\end{array}$ & $\begin{array}{l}41(8 \cdot 6) \\
12(7 \cdot 1) \\
8(10 \cdot 3)\end{array}$ & \\
\hline $\begin{array}{l}\text { Vibratory perception threshold }(\mathrm{V}) \\
\text { thumb } \\
\text { big toe }\end{array}$ & $\begin{array}{r}4 \cdot 1(0 \cdot 6) \\
11 \cdot 5(7 \cdot 3)\end{array}$ & $\begin{array}{c}5 \cdot 1(0 \cdot 8) \\
16 \cdot 9(5 \cdot 8)^{\star}\end{array}$ & $\begin{array}{r}5.0(0.8) \\
10.0(3.0)\end{array}$ \\
\hline $\begin{array}{l}\text { Sural nerve } \\
\text { CV (m/sec) } \\
\text { Amplitude }(\mu \mathrm{V})\end{array}$ & $\begin{array}{l}45 \cdot 6(3 \cdot 5)^{\star} \\
10 \cdot 2(6 \cdot 1)^{\star}\end{array}$ & $\begin{array}{l}42 \cdot 7(4 \cdot 4)^{\star} \\
3 \cdot 1(2 \cdot 7)^{\star \star}\end{array}$ & $\begin{array}{l}53 \cdot 1(2 \cdot 4) \\
29 \cdot 6(4 \cdot 7)\end{array}$ \\
\hline $\begin{array}{l}\text { Median nerve, motor } \\
\mathrm{CV}(\mathrm{m} / \mathrm{sec})\end{array}$ & $59 \cdot 0(3 \cdot 0)^{\star}$ & $55 \cdot 1(3 \cdot 6)^{\star}$ & $63.0(4 \cdot 5)$ \\
\hline $\begin{array}{l}\text { Peroneal nerve, motor } \\
\mathrm{CV}(\mathrm{m} / \mathrm{sec})\end{array}$ & $52.6(3.3)$ & $42.6(1.4)^{\star \star}$ & $51 \cdot 0(4 \cdot 7)$ \\
\hline
\end{tabular}

^HIV-group and AIDS-group compared to controls, $\mathrm{p}<0.05$.

$\star \star A I D S$-group compared to HIV-group, $p<0.01$.

Figure 1 Sensory conduction velocity along the sural nerve from the lateral malleolus to midcalf in $10 \mathrm{HIV}$ seropositive patients without AIDS lopen circles) and in 10 patients with AIDS (dots). The solid line indicates the normal mean, the thin lines indicate the $95^{\circ}$ o upper and lower confidence limits.

Figure 2 Amplitude of the sural nerve action potential. Symbols and lines as in fig 1 . Ordinate, amplitude in $\mu \mathrm{V}$, logarithmic scale.
Electrophysiological studies

The conduction velocity of the sural nerve was determined according to the method of near-nerve recording. ${ }^{13}$ In short, sensory fibres of the sural nerve were stimulated by needle electrodes at the lateral malleolus and
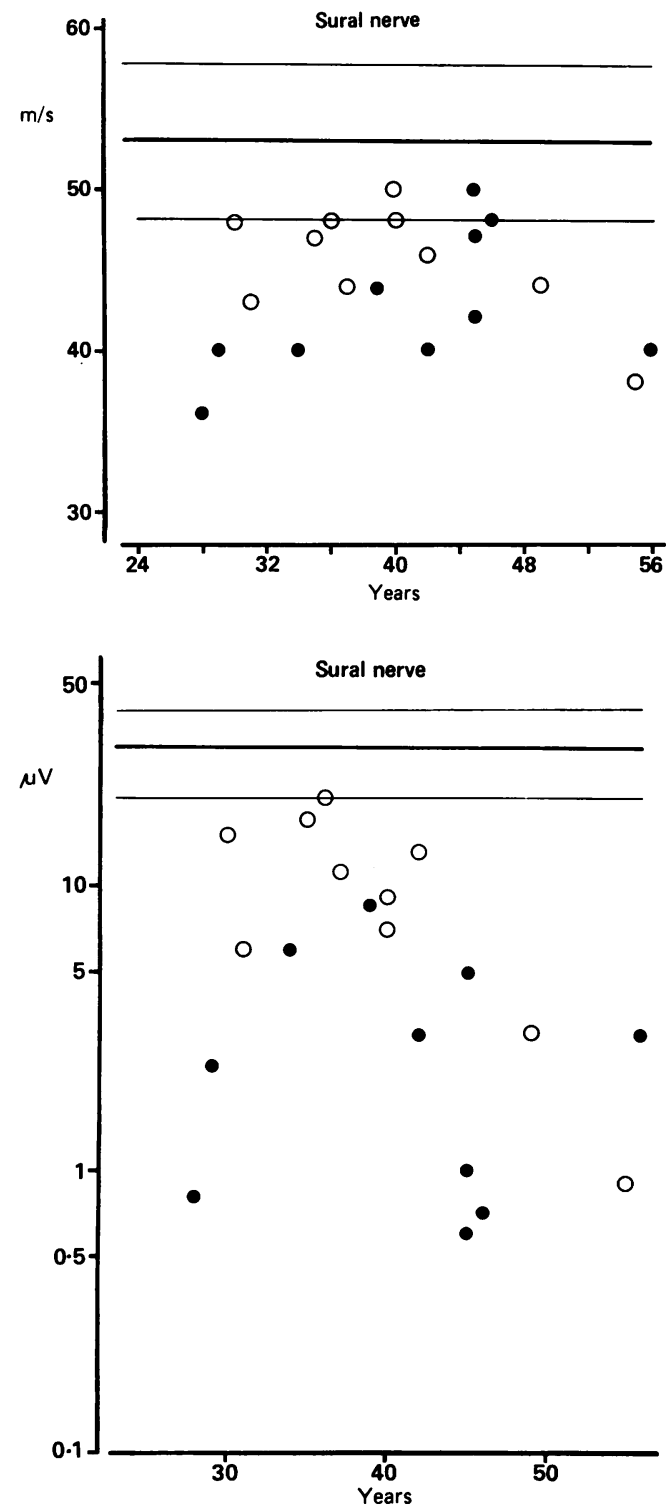

the evoked sensory action potential (SAP) was recorded via needle electrodes $12-15 \mathrm{~cm}$ proximal to the malleolus. The recording electrode was adjusted near the nerve until the largest sensory potential was obtained. When the SAP was less than $2 \mu \mathrm{V}$ electronic averaging of up to 1000 responses was used to identify a sensory potential. Motor conduction studies were performed on the median and peroneal nerves in the forearm segment and in the segment from knee to ankle, respectively, stimulating and recording with surface electrodes. To maintain a constant temperature of $34-36^{\circ} \mathrm{C}$ the arm and leg were heated by an infra-red heating element which was controlled by a thermo-couple on the skin. Findings in sensory and motor nerves in patients were compared with those in normal subjects matched for age. ${ }^{14}$

\section{STATISTICS}

Electrophysiological differences between patients with and without AIDS were tested by the unpaired $t$ test using a 0.0125 limit of significance (Bonferroni correction). $T$ test comparisons between patient and control groups as well as between treated and untreated groups were performed using a $\mathbf{0 . 0 5}$ limit of significance.

\section{Results}

The clinical features of the two groups of patients are summarised in Table 1. Age was similar in the two groups and there was no significant difference between duration of symptoms. All patients had symptoms of lower extremity sensory disturbances, paraesthesia or hypoaesthesia, suggesting a distal symmetrical polyneuropathy. Three of the HIV seropositive patients without AIDS and four of the AIDS patients had painful feet. Only three patients had motor symptoms (one HIV seropositive and two with AIDS). The clinical signs of neuropathy were generally mild, were more frequently observed in the AIDS patients, and affected mainly the lower extremities. No evidence of chronic inflammatory neuropathy was found. The vibratory perception threshold of the big toe was sig- 
Table 2 Sensory and motor conduction studies, vibratory and thermal thresholds in $12 \mathrm{HIV}$-seropositive patients followed for six to 15 months

\begin{tabular}{|c|c|c|c|c|}
\hline & \multicolumn{2}{|c|}{$A Z T$-treatment } & \multicolumn{2}{|l|}{ Controls } \\
\hline & $\begin{array}{l}\text { First } \\
\text { examination }\end{array}$ & $\begin{array}{l}\text { Second } \\
\text { examination }\end{array}$ & $\begin{array}{l}\text { First } \\
\text { examination }\end{array}$ & $\begin{array}{l}\text { Second } \\
\text { examination }\end{array}$ \\
\hline $\begin{array}{l}\text { Sural nerve } \\
\text { CV (ms) } \\
\text { Amplitude }(\mu \mathrm{V})\end{array}$ & $\begin{array}{c}44.9(3 \cdot 8)^{\star} \\
7 \cdot 2(4 \cdot 8)\end{array}$ & $\begin{array}{l}44.9(4.4) \\
11.6(8.4)\end{array}$ & $\begin{array}{l}49 \cdot 6(3 \cdot 4) \\
20 \cdot 0(10 \cdot 2)\end{array}$ & $\begin{array}{l}47 \cdot 6(2 \cdot 6) \\
17 \cdot 8(6 \cdot 1)\end{array}$ \\
\hline $\begin{array}{l}\text { Median nerve } \\
\mathrm{CV}(\mathrm{ms}) \\
\text { Amplitude (mV) }\end{array}$ & $\begin{array}{l}61 \cdot 7(5 \cdot 0) \\
13.0(7 \cdot 9)\end{array}$ & $\begin{array}{l}61.0(8.5) \\
11.0(2 \cdot 7)\end{array}$ & $\begin{array}{l}56 \cdot 3(2 \cdot 5) \\
14 \cdot 8(3.3)\end{array}$ & $\begin{array}{l}54 \cdot 3(2 \cdot 9) \\
14 \cdot 8(3 \cdot 7)\end{array}$ \\
\hline $\begin{array}{l}\text { Vibratory threshold } \\
\text { Thumb (V) } \\
\text { Big Toe (V) }\end{array}$ & $\begin{array}{r}3.6(0.5) \\
12.8(9.0)\end{array}$ & $\begin{array}{l}4 \cdot 0(0 \cdot 7) \\
9 \cdot 8(7 \cdot 7)\end{array}$ & $\begin{array}{l}4.3(0.5) \\
6.8(2.8)\end{array}$ & $\begin{array}{l}4 \cdot 8(1 \cdot 0) \\
6 \cdot 3(1 \cdot 3)\end{array}$ \\
\hline $\begin{array}{l}\text { Temperature threshold } \\
\text { Cooling }\left({ }^{\circ} \mathrm{C}\right) \\
\text { Warming }\left({ }^{\circ} \mathrm{C}\right)\end{array}$ & $\begin{array}{l}0.8(0.4) \\
2.1(2.5)\end{array}$ & $\begin{array}{l}1 \cdot 3(1 \cdot 2) \\
2 \cdot 5(2 \cdot 2)\end{array}$ & $\begin{array}{l}0.8(0 \cdot 6) \\
2 \cdot 1(2 \cdot 5)\end{array}$ & $\begin{array}{l}0.9(0.4) \\
2.1(2.5)\end{array}$ \\
\hline
\end{tabular}

*Values are mean $(\mathrm{SD})$.

nificantly increased in patients with AIDS only.

Table 1 summarises the electropysiological findings: conduction velocities of the median and sural nerve were slightly reduced in both groups of patients (fig 1). In the peroneal nerve AIDS patients only had slowing of conduction. The amplitude of the sural nerve action potential was considerably reduced in both groups of patients (fig 2).

HIV seropositive men without AIDS had better preservation of all four electrophysiological parameters than those who had developed the immune deficiency. However, only the reduction of the sural nerve action potential and the peroneal nerve conduction velocity were significantly better preserved in immune competent men.

The mean (SD) time between the first and the second examination was 10 (3) months, range 6-15 months. Most patients had symptoms for more than a year. The clinical stage of HIV infection ${ }^{15}$ remained unchanged in all patients. No significant clinical or immunological differences were observed between the first and the second examination except that a few patients in both groups had lost their deep tendon reflexes. Table 2 shows that no significant changes of sensory or motor nerve conduction velocity, amplitude or vibratory and temperature threshold occurred in the groups during the follow up period.

\section{Discussion}

In this study none of the ten HIV seropositive immune competent men with symptomatic polyneuropathy showed electrophysiological signs of demyelination characterised by profound slowing of the conduction velocity. Contrary to expectations immune competent patients had less slowing of conduction velocity than patients who had developed AIDS.

In both groups of patients the electrophysiological findings are compatible with an axonal polyneuropathy. We have previously shown that slight slowing of nerve conduction occurs in the majority of HIV seropositive immune competent subjects without symptoms of neuropathy and that the electrophysiological disturbances progress with time. ${ }^{1617}$ A possible explanation for the more severe elcctrophysiological impairment in the AIDS patients is that the duration of HIV infection in this group is longer. Our control group was a population with unknown sexual preferences. It is not known whether homosexual and heterosexual men have different peripheral nerve function. None of our patients used alcohol, medication or "recreational drugs" to a degree which can explain impairment of nerve function.

The electrophysiological results are most compatible with a distal axonal polyneuropathy affecting both sensory and motor fibres. Thus the degree of slowing in the sural, median and peroneal nerves in both groups of patients are well within the range expected from axonal degeneration of large myelinated fibres. ${ }^{18} 19$

The vibratory perception threshold of the big toe was significantly elevated in the patients with AIDS indicating a length dependent affection of the large myelinated afferent nerve fibres. ${ }^{20}$ We tested temperature thresholds in the HIV seropositive patients without AIDS and observed that the threshold for warming was very much elevated, mean (SD) was 3.7 $(2 \cdot 2){ }^{\circ} \mathrm{C}$; in normal subjects the upper $95 \%$ confidence limit was $2.1^{\circ} \mathrm{C}$, which indicates that the neuropathy also affects small unmyelinated fibres (preliminary finding).

Our results agree with other reports of electrophysiological studies on AIDS patients with associated distal polyneuropathy, ${ }^{6-10}$ with features of a dying back axonal neuropathy. An association between the affected part of the peripheral nervous system (myelin, axon, root) and the stage of the HIV infection has been proposed in several reports. ${ }^{467}$ HIV seropositive patients without AIDS are said primarily to have inflammatory demyelinating peripheral neuropathies. ${ }^{3421}$ In our study the clinical and electrophysiological evidence indicates that a distal symmetrical polyneuropathy also exists in HIV seropositive patients without AIDS.

It appears that every part of the nervous system is vulnerable to HIV infection. We have previously described clinical and electrophysiological evidence of myelopathy in patients with AIDS and in patients with HIV seropositivity but without AIDS..$^{516} \mathrm{It}$ is 
therefore difficult to localise lesions in the nervous system of HIV infected patients, and it is advisable to include electrophysiological studies in the evaluation of these patients.

In anecdotal reports, AZT treatment of HIV patients with associated neuropathy have shown conflicting results. Patients with HIV induced dementia and neuropathy have shown clinical improvement after administration of AZT. ${ }^{22}$ Another study showed clinical and electrophysiological improvement in one patient after two months of AZT treatment. ${ }^{23}$ In a third study three patients with predominantly sensory neuropathy were given AZT and none improved. ${ }^{7}$ No systematic trial of AZT has been published. In our group of HIV patients with neuropathy we did not observe any significant improvement of the clinical and electrophysiological measures during AZT treatment. No deterioration, however, took place in our control subjects during the follow up period indicating that our observation period might be too short.

The aetiology and pathogenesis of peripheral neuropathy associated with HIV infection is uncertain. HIV virus has been cultured from peripheral nerves ${ }^{24}$ and viral particles have been identified in a sural nerve biopsy ${ }^{8}$ suggesting direct viral infection of the nerve. A circulatory factor which attacks peripheral nerves, making them vulnerable to virus infection, could also play a role. ${ }^{6}$ Infection of peripheral nerves with HIV or opportunistic viruses such as cytomegalovirus is strongly suspected in patients with distal symmetrical polyneuropathy, but has never been demonstrated. Further studies of this condition as well as its response to treatment are needed.

1 Snider WD, Simpson DM, Nielson S, et al. Neurologic complications of acquired immunodeficiency syndrome: analysis of 50 patients. Ann Neurol 1983;14:403-18.

2 Levy RM, Bredesen DE, Rosenblum ML. Neurological manifestations of the acquired immunodeficiency syndrome (AIDS): experience at UCSF and review of the literature. $J$ Neurosurg 1985;62:475-95.

Dalakas MC, Pezeshkpoor GH. Neuromuscular diseases associated with human immunodeficiency virus infection. Ann Neurol 1988;23(suppl):38-48.
4 Parry GJ. Peripheral neuropathies associated with immunodeficiency virus infection. Ann Neurol 1988;23(suppl):49-53.

5 Helweg-Larsen S, Jakobsen J, Boesen F, et al. Myelopathy in AIDS: A clinical and electrophysiological study of 23 in AIDS: A clinical and electrophysiological study

6 Miller RG, Parry GJ, Pfaeff W, et al. The spectrum of peripheral neuropathy associated with ARC and AIDS. Muscle Nerve 1988;11:857-63.

7 Cornblath DR, McArthur JC. Predominantly sensory neuropathy in patients with AIDS and AIDS-related complex. Neurology 1988;38:794-6.

8 Bailey RO, Baltch AL, Venkatesh R, et al. Sensory motor neuropathy associated with AIDS. Neurology 1988;38:886-91.

9 Lange DJ, Britton CB, Younger DS, et al. The neuromuscular manifestations of human immunodeficiency virus infections. Arch Neurol 1988;45:1084-8.

10 So YT, Holtzman DM, Abrams DI, et al. Peripheral neuropathy associated with acquired immunodeficiency syndrome. Prevalence and clinical features from
tion based survey. Arch Neurol 1988;45:945-8.

11 Nielsen VK. The peripheral nerve function in chronic renal failure. An analysis of the vibratory perception threshold. Acta Med Scand 1972;191:287-96.

12 Fowler FJ, Caroll MB, Burns D, et al. A portable system for measuring cutaneous thresholds for warming and cooling. J Neurol Neurosurg Psychiatry 1987;50:1211-15.

13 Behse F, Buchthal F. Normal sensory conduction in the nerves of the leg in man. $J$ Neurol Neurosurg Psychiatry 1971;34:404-14.

14 Rosenfalck P, Rosenfalck A. Electromyography, sensory and motor conduction: Findings in normal subjects. Laboratory of clinical neurophysiology, Rigshospitalet,
Copenhagen

15 Centers for Disease Control. Classification system for human T-lymphotrophic virus type III/lymphadenopathy-associated virus infections. $M M W R$ 1986;35: 334-9

16 Smith T, Jakobsen J, Gaub J, et al. Clinical and electrophysiological studies of human immunodeficiency virusseropositive men without AIDS. Ann Neurol 1988;23:295-7.

17 Jakobsen J, Smith T, Gaub J, et al. Progressive neurological dysfunction during latent $\mathrm{HIV}$ infection. $\mathrm{Br} \mathrm{Med} J$ 1989;299:225-8.

18 Gilliatt RW. Nerve conduction in human and experimental neuropathies. Proc $R$ Soc Med 1966;59:989-93.

19 Behse F, Buchthal F. Sensory action potentials and biopsy of the sural nerve in neuropathy. Brain 1978;101:473-93.

20 Galne DB, Pallis CA. Vibratory sense: A critical review. Brain 1966;89:723.

21 Cornblath DR, McArthur JC, Kennedy PGE, et al. Inflammatory demyelinating peripheral neuropathies associated with human T-cell lymphotropic virus type III infection. Ann Neurol 1987;21:31-40.

22 Yarchoan R, Berg G, Prouwers P, et al. Response of human immunodeficiency virus associated neurological diseases to $3^{\prime}$-azido-3'-deoxy-thymidine. Lancet 1987; i:132-4.

23 Dalakas MC, Yarchoan R, Spitzer R, et al. Treatment of human immunodeficiency virus-related polyneuropathy human immunodeficiency virus-related polyneuropathy
with $3^{\prime}$-azido-2', $3^{\prime}$-dideoxythymidine. Ann Neurol with 3'-azido-2', 3'
1988;32(suppl):92-4.

24 Ho DD, Rota TR, Schooley RT, et al. Isolation of HIV from cerebrospinal fluid and neural tissues of patients with neurologic syndromes related to the acquired immunodeficiency syndrome. $N$ Eng J Med 1985;313:1493-7.

25 de la Monte SM, Gabuzda DH, Ho DD, et al. Periphera neuropathy in the acquired immunodeficiency syndrome. Ann Neurol 1988;23:485-92. 